\title{
Syzygy and the cyclic nature of Arts Practice
}

\author{
Miik Green, Curtin University of Technology, Australia
}

\begin{abstract}
This paper examines contemporary arts practice and resistive modes of exchange. It argues for a framework recognising the importance of borders, specifically to interdisciplinary dialogue. In English, the term syzygy is used in astronomy to signify an alignment of three planetary bodies. This concept (beyond its Greek roots) has become an investigative model in approaching my practice, wherein a union of opposites reach uncomfortable resolution. I use my arts practice and select examples of key practitioners to reinforce this position along with illustrations from theorists to present several new ideas. My visual arts practice utilises unlike materials that resist one another, creating heterogeneous forms. This transformative action results in disequilibrium: opposing forces of energy and exchange. Without this action, the same structures would inevitably blend into homogeneity. Thus on a material level, resistance produces a necessary clarity - through unseen force. The same opposing force is vital to interdisciplinary modes of exchange, towards a resistant, collaborative dynamism. This paper plays with the idea of a syzygetical model, of engaging mutually incompatible fields, from the artist's studio to engagement in arts practice.
\end{abstract}

Keywords: Syzygy, Arts Practice, Conflict, Resistance, Dialogism

\section{Modes of Exchange}

$\mathrm{T}$ This paper centres around syzygetical arrangements, from the making and creating of art to the wider implications in arts practice. Etymologically, syzygy ${ }^{1}$ is a term drawn from the Greek language, meaning 'yoked together' when oxen were linked in labour. Here, it is used allegorically, describing the struggle or resistance that can be found in a creative practice. In exploring this idea, I use examples from my visual arts practice as well as drawing from the work of current practitioners. In How to Use Your Eyes, James Elkins suggests several alternative ways of viewing our surrounding world, from the natural and the manufactured to objects and phenomena that we may encounter. As he notes: 'It's about stopping and taking the time simply to look, and keep looking, until the details of the world slowly reveal themselves. I especially love the strange feeling I get when I am looking at something and suddenly I understand - the object has structure; it speaks to me' $(2000,9)$. Like Elkins' vision, the ideas in this paper suggest a new way of approaching arts practice and creativity.

My paintings have been described as luscious, sexy and entrancing; some pieces have been licked, grabbed and even fondled at exhibitions. It has been said that they demand to be stroked or exist as objects of desire. While the initial reaction to the work is visual, on further investigation the works also prompt a bodily response: some surfaces are highly glossed, others are translucent or opaque, but all contain a similar liquid-like coating. Beyond the slick/sensual surface readings (the initial attractant) - there is an underlying tension, between order and chaos in creation. The forms are held in active limbo, amidst the living and the dying, between breath and asphyxia.

The works rely on resistance, dissonance and opposition at a material level: separating and reacting while the resin sets. The process of catalysis seals these interactions, creating mesmerising structures encased in a glass-like sheet. While many of the images in this paper are details from larger works, they are key to the central idea of syzygy and embody a resistant tension. The structures and patterns that emerge through this process of reaction seem to reference the organic, the biologic. Whilst appearing plant-like, a viewer sees a resonance and resemblance with the cellulose-like forms in what also appears as human muscle tissue. This ambiguity opens the work up to ideas of life and death; the science of sustaining life and the struggle to inhibit death. In a similar cyclic manner, and analogous to my approach to arts practice, revelation can be seen in opposition, pressure and stress. In order for these forms to be revealed, they must be sealed, enclosed and concealed.

${ }^{1}$ From the Greek word suzugos ( $\sigma u ́ \zeta$ 
The process of combining resistant materials involves mixing, pouring, injecting and dragging liquids across an aluminium 'canvas'. Pigments and chemicals combine within the resin, blooming, striating and pulsing apart as the fluid materials solidify. They appear both celestial and cellular - as if one has zoomed into the body's inner morphometry, or outward in cosmic survey. We see atoms and atmospheres, a pangaean microscape. As the scientist encases tissue between glass slides, planetary arrangements are perceived through the astronomer's lens. To this end, the works vary in size from $45 \mathrm{x} 45 \mathrm{~cm}$ to $400 \mathrm{x} 200 \mathrm{~cm}$ in scale, comprising mixed media applied to aluminium panels.

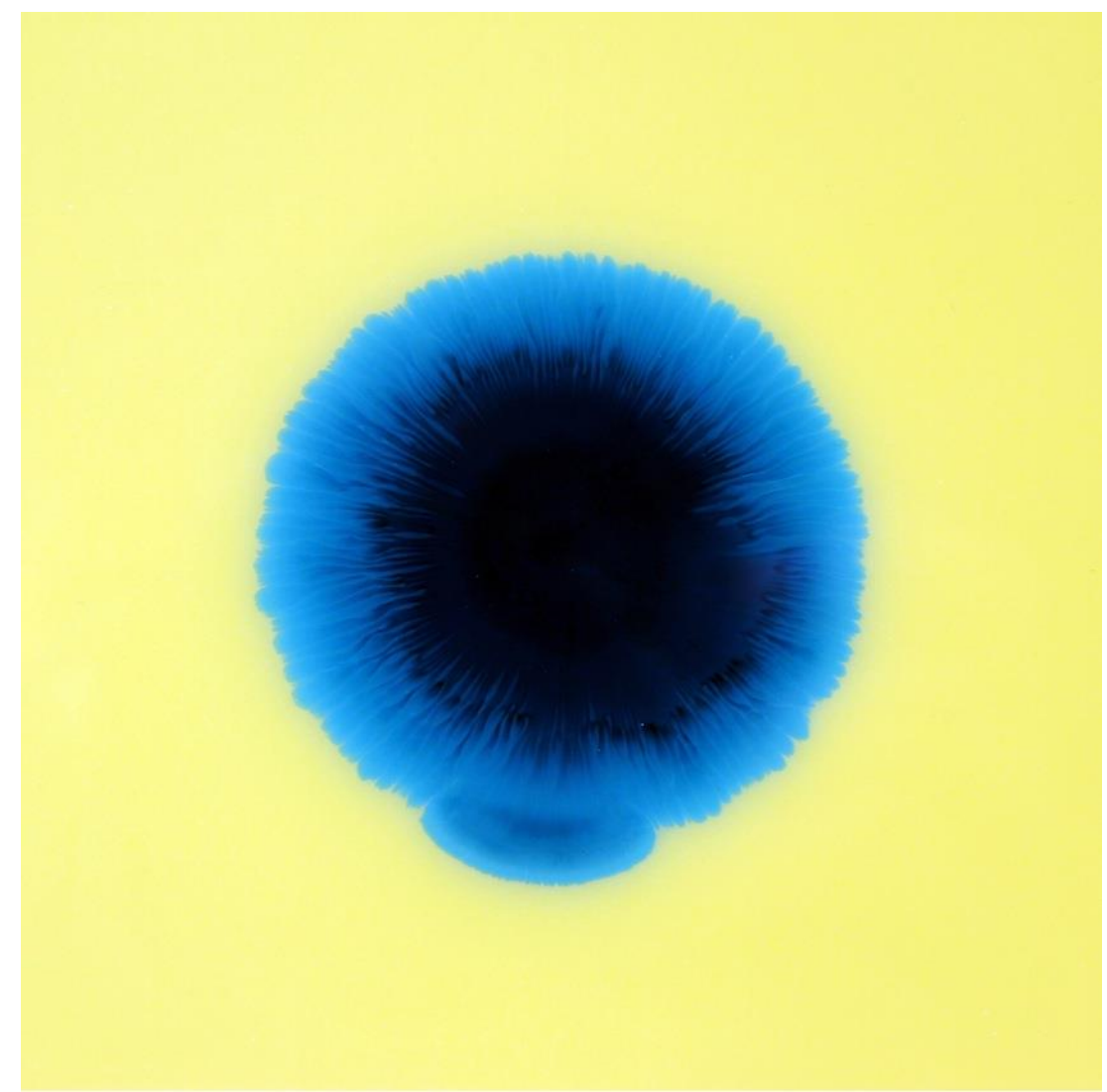

Fig 1: Xylem series: Terfesia8 (detail). Mixed media on aluminium. 185 x $185 \mathrm{~cm}$. Source: (Miik Green, photo courtesy Ben Phillips, 2012.

In Fig 1 we see a blooming black/blue form emerging from a field of yellow. While the form appears initially floral-like, reminiscent of petals spreading or opening, on sustained glance it is also pulling, sucking and receding. It is this pulse - that of materials suspended in tension - that pulls and pushes. It rejects and embraces, it respires and suffocates; the aesthetic throb becomes a dissonant distractor. The viewer now enters an arrangement that simultaneously presents a new blossom opening or an ageing bud closing; systems of growth and decay in which varying states of life and death seem to co-exist.

I often find that poetry, rather than traditional writing helps to convey certain concepts. Exit: Entropy, Enlightenment. 


\author{
Left, enlightened \\ Through liquid space \\ emergent, \\ rising towards light, heat- and whiteness, \\ an ambassador sent \\ for the struggle yet \\ from the coolness of below. \\ Unready, unsteady for the insurrection \\ That will surely follow, exerted already. \\ Inhaling a substance, a period of lightness \\ of lovelessness, lightness in the whiteness \\ but it is coming ... \\ and in pure regret, \\ regress, pummelled. \\ closing eyes in impact, \\ the noiseless roar, \\ of transfiguration. \\ Perspires, respires \\ this transfusion as transition - \\ set in space, the crux \\ between atrophy and activity \\ held at the point of \\ entropy and enlightenment
}

Miik Green, 2014

It is conflict that produces these mesmerising structures, motionless forms trapped in imperceptible movement. The materials are immiscible; they repel and react, yet in combination create and transform. It is in this process, the planned approach to instability, that the poetics of syzygy are revealed. The resistance seen in these works becomes a central body of three (amidst two oppositional materials) between which syzygy is positioned. Expanding this idea might see syzygy as action between artist and work, or the maker and the making. In acknowledging this as a key factor of transformation, the artist's role as maker can be redefined as facilitator, in enabling the materials to contribute in the making process. Here the artist steps back, loosening their grip on control in order to embrace a creative instability.

'Some of us have begun to realise that we are part of the continual interaction, exchange and transformation of energies that is nature' John Grande

From this point, conflicting interactions that happen materially in the studio become signifiers, modes of exchange within arts practice. They open a door to wider possibilities of unlike interaction, ie. between artist and architect, gallerist and client, or public art and the public. Artists such as Richard Serra, Sol LeWitt and Anish Kapoor, whose respective practices stretch into the public realm, understand these complex interactions. These artists produce works for both the gallery space and the built environment/landscape, and share a consistency of style operating between these platforms. Kapoor's celebrated 2006 sculpture, the gleaming, legumelike Cloudgate stands as a monument to the artist's resistance and persistence in the face of bureaucracy. The sculpture rests triumphant in light of the potential engineering, budget and environmental issues that could have plagued (and absorbed) it.

The same engineers that said 'this shape cannot be produced,' or the accountants discounting 'a non-feasible project' appreciate the artwork, see its value beyond material manipulation or monetary mandates. It has been embraced by the public and adopted as a Chicago icon: a striking object, the work Kapoor is famous for in the United States. Its reflective surface entrances the 
viewer while encompassing the city of Chicago, as buildings stretch and augment along its curvilinear surface. It fluctuates between the material and the spiritual, speaking of the passing and pausing of time - of permanence and transience. Given the issues Kapoor would have to surmount during commissioning, it is a wonder that the work was ever approved. And what if bureaucrats had won this fight? Would the sculpture have had less impact or recognition? Would it have maintained its artistic integrity? It is this gap, the tension-between, where syzygy is manifest, in active/resistant separation - where the artist chooses either to desist or resist.

Serra acknowledges this divide. He presents the difference (between sculpture and architecture) in terms of distinctions and impositions - of functional and non-functional agendas. He expresses this notion saying: "What you find in place is an assimilation of any art style, eclecticism, kitsch. There is an attempt to diminish the distinction between architecture and sculpture as architects overlap the non-functional determination of sculpture into their constructs. The converse is not the problem of my sculpture' (1994, 33). His view echoes LeWitt's sentiments, an artist would occasionally make uncomfortable work for comfortable spaces. Much like Serra, he saw the disparity between the power structures he worked with (and under/against) and his practice. His work was sometimes subversively simplistic: relatively reactant considering the relative ease in which his sculpture was generally accepted. Nicholas Baume considers this relationship, stating: 'Memorial to the Missing Jews refuted the healing potential of the memorial, instead thematizing processes of division, obstruction and intractability. Within weeks it was covered in political graffiti; months later it was jackhammered from the site' $(2011,76)$. Baume points to the reactionary here, the artist aware of a conformist nonconformity. Acts such as these reinforce art's uneasy relationship with structures that exist outside it, syzygetically positioning the artist between authorities, institutions and the public.

While the artist may appreciate their role in public art, they should prepare for the resistance (and conflict) that can emerge through the procedure. Serra is an artist aware of these dynamics and the complex power structures that create this resistance. His controversial sculpture Tilted Arc serves as reminder of disequilibrium (here between artist and public, art and politics) and the socio-political dilemmas that engulfed the work. Tilted Arc was commissioned in 1981 by the Arts-in-Architecture program funded by the United States General Services in Manhattan, New York. It was removed eight years later in 1989 following a lawsuit and much public debate. When interviewed on his position he stated: 'It's really the obligation of the sculptor to define sculpture, not to be defined by the power structure that asks you, that while you put your sculpture up, to please make this place more beautiful. I find that a totally false notion, because their notion of beauty and my notion of...sculpture are always, invariably, at opposite ends' (Senie (Apud) 2002, 24). What would Tilted Arc look like today, if it were still in-situ? Would it still be generating controversy or have settled (albeit uncomfortably) within the landscape?

Serra's experience serves as a reminder that contrasting agendas, social issues and power structures are often revealed through conflict. Ultimately in the case of Tilted Arc, resolution equated to removal. Having an awareness of these binary oppositions equips the artist to enter negotiations, often outside arts practice; where the boundaries of arts practice are tested, the artist is forced to reposition, to react and respond. It is within this disequilibrium, and the energy expended between two bodies that tension's transformative power can be visualised. Australian Artists Guy Ben-Ary and Kirsten Hudson initiated the in Potēntia Project, artistic research that combined foreskin cells with brain neurons. Their resultant paper discusses the dynamics of this collaboration, uniting dissimilar viewpoints as the project expanded to include a designer and scientist. 


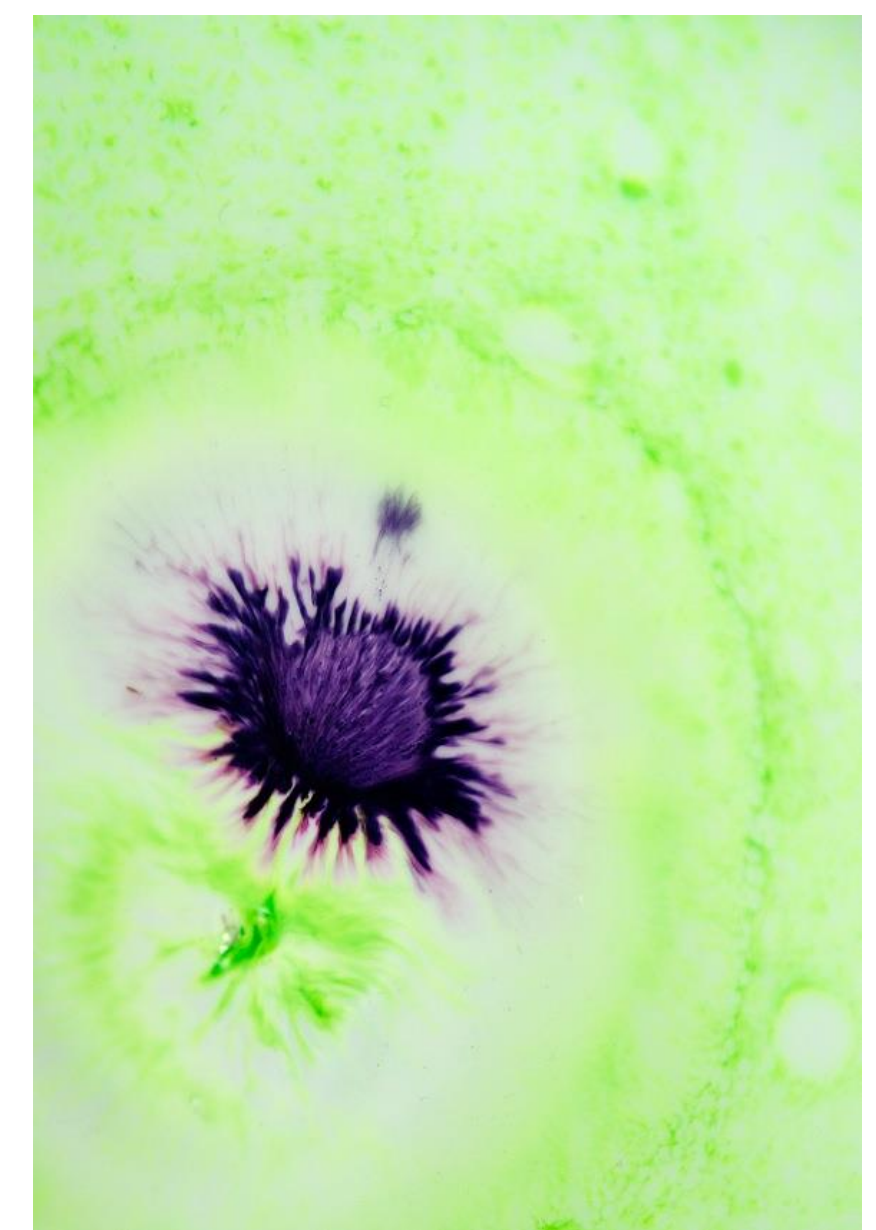

Fig 2: Xylem series: Meiosis (detail). Mixed media on aluminium. 185 x $185 \mathrm{~cm}$. Source: (Miik Green, photo Ben Phillips, 2013.

In The Dynamics of Collaborative Resistance, Hudson and Ben-Ary see interdisciplinary conflict as productive to collaboration, and value it as a dynamic, active contributor to research, stating: 'Although we tend to think that creativity thrives best when constraints are removed, in fact the opposite is true; creativity thrives when people are challenged by constraints that inconvenience them and forces individuals to be inventive, innovative and creative. Constraints provide us with the opportunity to get rid of everything that is irrelevant' $(2013,4)$. Similarly Oron Catts, director of SymbioticA ${ }^{2}$ likens the artist's charge as a challenge to non-compliant systems, in a bid to 'try and deliver an artistic action against the resistance of utility, exposing the artproof nature of our times' $(2012,29)$.

Baume, now discussing Kapoor's work, offers his suggestions on the dynamics of creativity: 'Creative chaos: a dynamic struggle to find a way, grappling with moments of clarity, elusiveness of thoughts and means to find a way, a form, a solution that might also mean the destruction of what existed in order to move forward. We sense two states pulling at us. But rather than oppositional, both are needed to bring forth something new' $(2008,127)$. While his observations broadly explain the creative struggle, he anticipates outcome or resolution over the making process, even the destruction of what existed. Baume negates a key factor in the creative process: the struggle. He argues from a dialectic position that is problematic in light of what

${ }^{2}$ SymbioticA is an internationally renowned wet-biology lab, where scientists collaborate with artists to develop artistic projects. It operates from the University of Western Australia. 
Serra, LeWitt and even Kapoor have experienced. Theirs is a dialogic struggle, where resistance is borne out through their work, from studio to public space. In light of these ideas, how does the contemporary artist approach resistance? Is it time to consider these arrangements through Elkins' lens?

\section{Dialogic Dioramas}

If there is a fundamental disconnect between art and the external structures it may encounter, where does this position the artist, or their role within society? And what then of the discourse of arts practice? Art inhabits a dialogic space, a constantly changing, shifting site, that is set-intension. A diorama acts as a suitable metaphor, where the artist operates from an allencompassing viewpoint. Russian philosopher, Mikhail Bakhtin first coined the term 'dialogic', to describe the dynamic meaning that is created through multiple or disparate voices. The term counters a Hegelian dialectic in terms of operation, motives and meaning; where meaning is conveyed through dialogism, it is open to, and builds from, new interpretations, embracing differing voices. It is an engaging, organic dialogue that is in constant motion; a self-sustaining cycle rather than a closed circuit. In arts practice, a dialectic arrangement is inadequate where necessity for outcome or reliance on result favours product over production. It looks towards resolution, utilising language such as 'united', 'integrated' or 'synthesised', from which a voice or singular meaning is drawn.

By visualising art (and by extension, the wider discourse of arts practice) through a dialogic lens, we see a complex diorama unfold, one where art and interactions, and interdisciplinary engagements are yoked together whilst discrete. Under the pressure of resistance, blending, merging or absorbing become delineations, distinct elements and divisions. Where Fig 3 appears liquid-like and muddy, on closer inspection the detail reveals that instead of mixing, the resistant trails form fine lines - evading adsorbtion ${ }^{3}$. The oily sections, thick and viscous, meander through a bright yellow swathe, an overflowing bilge pump. It appears surficial, geographic tendrils seen from above, or a living river system running through tributaries. It is the stagnant, polluted pond where oozing scum-patterns develop in stasis.

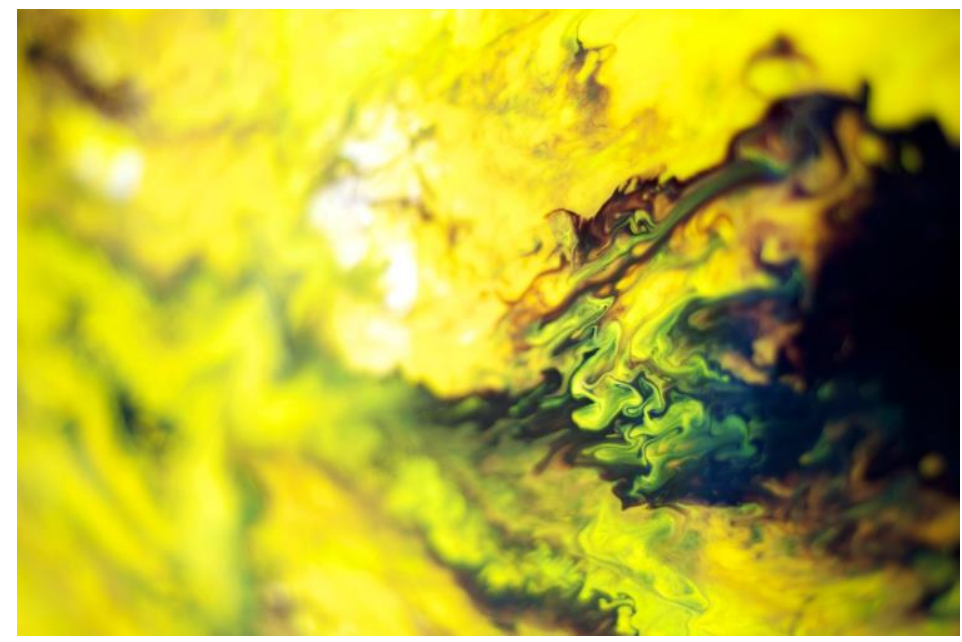

Fig 3: Xylem series: Haplostele 13 (detail). Mixed media on aluminium. 107 x $107 \mathrm{~cm}$ Source: CMiik Green. Photo courtesy Ben Phillips, 2013.

\section{Cyclicity and the Syzygetical}

\footnotetext{
${ }^{3}$ Adsorbtion is the surface-based process of molecular bonding, similar to surface tension. It is used here in the context of escaping any physical adhesion.
} 
American artist Robert Smithson equated his landscape interventions with the idea of entropic systems. In works such as 1970s Spiral Jetty or Rundown (1969), Smithson manipulated geological matter with industrial materials, exemplifying the inherent destruction in creation. Spiral Jetty is an iconic earthwork situated in the Great Salt Lake, Utah. Assembled from rocks, salt and mud, the work turns inward, coiling towards a central point. It is a monument to the flawed degeneration and regeneration of systems: while appearing ordered there is also a chaos, the uncontrolled force of nature, an unsustainable loop. The artist toys with ideas and concepts between growth and decay, highlighting the way we view and interact with the structures around us. For example, in Smithson's entropic vision, we might see the terms composing and composting become contradictory elements, yet also as points in a cycle. To compose is to build, to add - towards a composition, while compost is to deteriorate, to break down towards separation. Both concepts sit within a revolution, as oscillating points set in motion; they are set in a direction towards each other, where growth emerges from decay and yet in turn, these same organisms will eventually disintegrate.

The flaw Smithson perceives in socio-political systems surmounts to an organised futility - a cyclic descent towards expended energy. This breakdown is reflected in his works where large land pieces slowly break down and submit to the same entropic laws: he sees futility yet purposefully resists. The otiose undertaking of resistance here, the expended effort is not in vain; ultimately the process points to a greater failure, that of organisations as a whole. Smithson sees the Ecclesiastical hopelessness of these systems, yet chooses to respond as the artist, the outsider. He looks towards eventual collapse, where meaning and new structures emerge through deterioration, stating: 'So you have this stalemate and I would say that's part of the clashing aspect of the entropic tendency, in other words two irreconcilable situations hopelessly going over the same waterfall' $(1971,307)$.

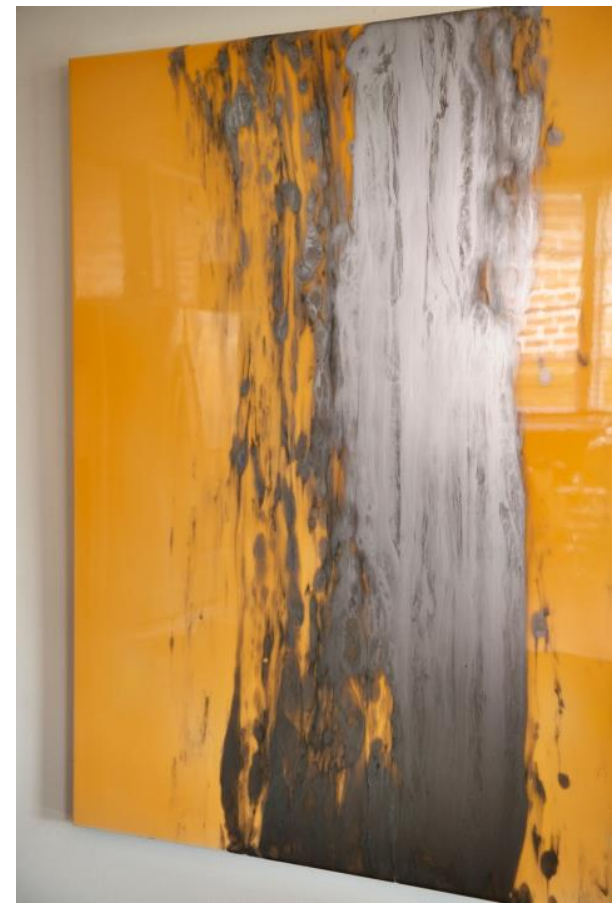

Fig 4: Xylem series: Haplostele 13 (detail). Mixed media on aluminium. 107 x $107 \mathrm{~cm}$ Source: CMiik Green. Photo courtesy Jody D'Arcy/Jo Carmichael, 2013.

What this dialogue depicts, outside the arts practice setting, are the social, political and cultural implications seen in the social/political/economic organisations that surround us. Seen through a syzygetical lens (embodying difference, held in tension) these interactions transform. In other words, meaning emerges through struggle, and clarity is brought forth in tension. In 
Ideas And The Synthesis Of Difference Deleuze states that the limit 'must be conceived not as the limit of a function but as a genuine cut [coupure], a border between the changeable and the unchangeable within the function itself' $(1994,218)$. Deleuze succeeds in establishing that there are dialectic arrangements surrounding us, yet the idea of synthesis is a limiting one in terms of resolution. Lyotard establishes these problematic dialectic arrangements as having to exist, resolved in their fundamental incompatibility. He titles this paradox as the differend, the '...unstable state and instant of language wherein something which must be put into phrases yet cannot be' $(1988,13)$. In disparity, separate elements are seen together, creating new meaning as opposed to blending, morphing or amalgamating (which sounds like a description of bad art, of poor execution or sloppy technique). The idea of the differend rests on its ability to create meaning through distinct combinations as opposed to the current language of arts practice, where emphasis is placed upon words like 'integration' and 'synthesis'. In light of this premise such terms become obsolete.

\section{Conclusion}

So how does the contemporary practitioner position their practice when encountering resistance? And what of the avenues provided for art-making, or opportunities? If art - and the art-making processes - are by nature incompatible in their exchange (with culture, commerce etc) what does it say about the seamless, the integrated? Can this 'bridging' discourse inform us about motive, agendas and intent regarding the arts? In the public art realm, terms such as 'Wayfinding' and 'Visual Markers' often ask a coded question: are you, the artist, willing to do signage? This language is disarmingly anti-art, the mediocre tones of neutrality where bureaucracy subtly reframes the creative process. These are conditional limits placed on an artistic practice that promise everything while commit to nothing. Has cultural conformity bred this inability for us to see, therein birthing an epidemic of impotent art? Here we see the potency of resistance in all its forms, from art-making to the artist interacting with the world: together/apart.

In concluding, I suggest that the promotion of an 'integrated art' merely reflects the general trend toward cultural homogeneity. If art does not, by nature, integrate, then what is 'integrated art'? Writer John Grande cites the need for disunified unity within the cultural setting, stating 'If the cultural mix appears to be taking place on the surface, it largely results in the homogenization of world cultures, not a mutual respect for cultural differences' $(2004,24)$. What Grande and Lyotard see, beyond Deleuze, is an outcome that regards interaction and energy over resolution, where transformative possibilities surpass those that strive solely for resolution. From this position we see arts practice within its dialogic diorama: set in tension between disparate structures. It is this struggle, or resistance, that allows for transformation: it is within Lyotard's differrend and Smithson's clash that this metamorphosis becomes unveiling-in-action.

This way of seeing discerns the tangible in the ephemeral, sees an instability in balance, and embraces the disparate-in-unity. In allowing for heterogeneous interventions such as these, the idea of syzygy becomes pivotal, it is action-towards-transformation. It releases the artist from traditional ways of making and modes of approaching arts practice and beyond. It is here that tension, antagonism and the struggle involved in creating becomes apparent. It invites the unplanned, unintended, pulsing between stasis and movement. It is in this exchange that the floral is drawn into the void, where the cavity in turn blooms, echoing again the cyclic and syzygetic nature of arts practice.

\section{Acknowledgements}

Dr Michael Seats, Professor John Teschendorff, Dr Ioannis Michaloudis, and Chris Malajczuk. 


\section{REFERENCES}

Baume, Nicholas. 2008. Anish Kapoor. Boston: MIT Press.

Baume, Nicholas. 2011. Sol LeWitt: Structures. New York: Yale University Press.

Catts, Oron. 2012. "Bullet Proof Skin vs. Utility Proof Art or When a Symbolic Gesture is Seen as a Real Action." In Bullet Proof Skin Exploring Boundaries by Piercing Barriers, edited by Jalila Essaidi, 29-31. London: Eindhoven.

Deleuze, Gilles. 1994. Difference And Repetition. Great Britain: Athlone Press

Elkins, James. 2000. How To Use Your Eyes. New York: Routledge.

Grande, John. 2004. Balance: Art and Nature. Montreal: Black Rose Books.

Heidegger, Martin and William Lovitt. 1982. The Question Concerning Technology and Other

Essays. New York: Harper Collins.

Hudson, Kirsten, G. Ben-Ary, M. Lawson and S. Hodgetts. 2013. The Dynamics of Collaborative Resistance: Negotiating the methodological incongruities of art, cultural theory, science and design. ISEA Conference, Sydney 7th - 16th June 2013

Lyotard, Jean-Francois. 1988. The Differend: Phrases in Dispute. USA: University of Minnesota Press.

Senie, Harriet (Apud). 2002. The Tilted Arc Controversy. Dangerous Precedent? Minneapolis: University of Minnesota Press.

Serra, Richard. 1994. Richard Serra: Writings Interviews. Chicago: The University of Chicago Press.

Smithson, Robert. 1996. Robert Smithson: The Collected Writings. Berkeley: University of California Press.

\section{ABOUT THE AUTHOR}

Miik Green: Visual Artist and Researcher, PhD Candidate, School of Design and Art, Curtin University of Technology, Perth, Western Australia. 